\title{
Severing the Links between Education and Careers: the Sobering Experience of China's Urban Schools, 1968-76
}

\section{Jonathan Unger}

Ronald Dore's The Diploma Disease [1976] has shown convincingly how the educational systems of many of the Third World countries have been distorted by the desperate desires of their students to win modern sector jobs. As the school system expands, ever higher educational credentials become necessary to obtain such jobs, and the reputations of schools and the careers of teachers can become increasingly dependent upon their students' rate of success in getting through higherschool entrance examinations. In much of the Third World, as Dore points out, the end results can be crippling. Students spend years in a rote cramming that will have little relation to their own later lives; the contest to climb the school ladder implicitly teaches them to view the most common occupations of their society with disdain; and most of them are then consigned to those very occupations as 'failures'.

In the 1960s, China's school structure somewhat resembled the educational structures of other late-developing countries. Entrance examinations helped determine which of the students were able to enter each higher level of education; the competition among students was tight; and many Chinese high schools, especially in the cities, competed to attain a high university entrance rate. Success in this earned the school a high reputation. (The important exceptions to this competition, as we shall later observe, were the vocational schools.)

In the aftermath of the 1966-68 Cultural Revolution, China's 'radicals' (that is, Mao and the group that is now pejoratively called the Gang of Four) destroyed this earlier school structure. Their principal motive was to provide better opportunities to young people from proletarian families. Since the children of the old prerevolution intelligentsia and merchants were among the best students, the examination system had favoured them. Thus all examinations that sorted and stratified students were to be abolished. Schooling was to be restructured so as to level out the gaps between students from different backgrounds. To promote this, after 1968 in major cities like Canton, education was supplied to all youths through senior high school.
(Financially this was made possible by shortening the entire school curriculum by two years.) Then, so as to sever entirely the links between classroom achievements and upward mobility, all the young people graduating from high school were assigned directly to jobs, with no account taken of their academic records when devising these job postings. The choice of which young people could go on to higher schooling was left to the places of work, purportedly on the basis of a young worker's performance on his job.

Though this new scheme's intent was primarily to improve the chances of working class children, these radical changes were similar to those Dore has put forward as a possible remedy for the 'diploma disease' [Dore 1975: 142-53]. But the programme as practised in China proved unworkable. Between 1968 and Mao's death in 1976, most of China's urban ${ }^{1}$ students simply stopped paying attention in class.

Admittedly, when this new structure of education was introduced in 1968, China's urban schools faced enormous problems that would have hampered any educational venture. Students had been running loose on the streets during the two chaotic years of the Cultural Revolution, and the schools were having difficulty getting them readjusted to the routine of school life. The teaching profession was demoralised; the textbooks were haphazardly devised; and the curriculum was subjected to exceedingly narrow ideological constraints. In fact, many of the schools initially played it safe by having their students concentrate solely on memorising Mao quotes [Unger forthcoming].

But by the 1970s, China provided a somewhat better test case of whether it is feasible to divorce education from the contest for careers. Though China's schools still faced grave administrative problems, the turmoil and confusion of the Cultural Revolution was receding into memory; the textbooks were no longer heavily burdened

I To avoid misunderstanding, note the qualification in the title of this article, that only urban schools are discussed here. 


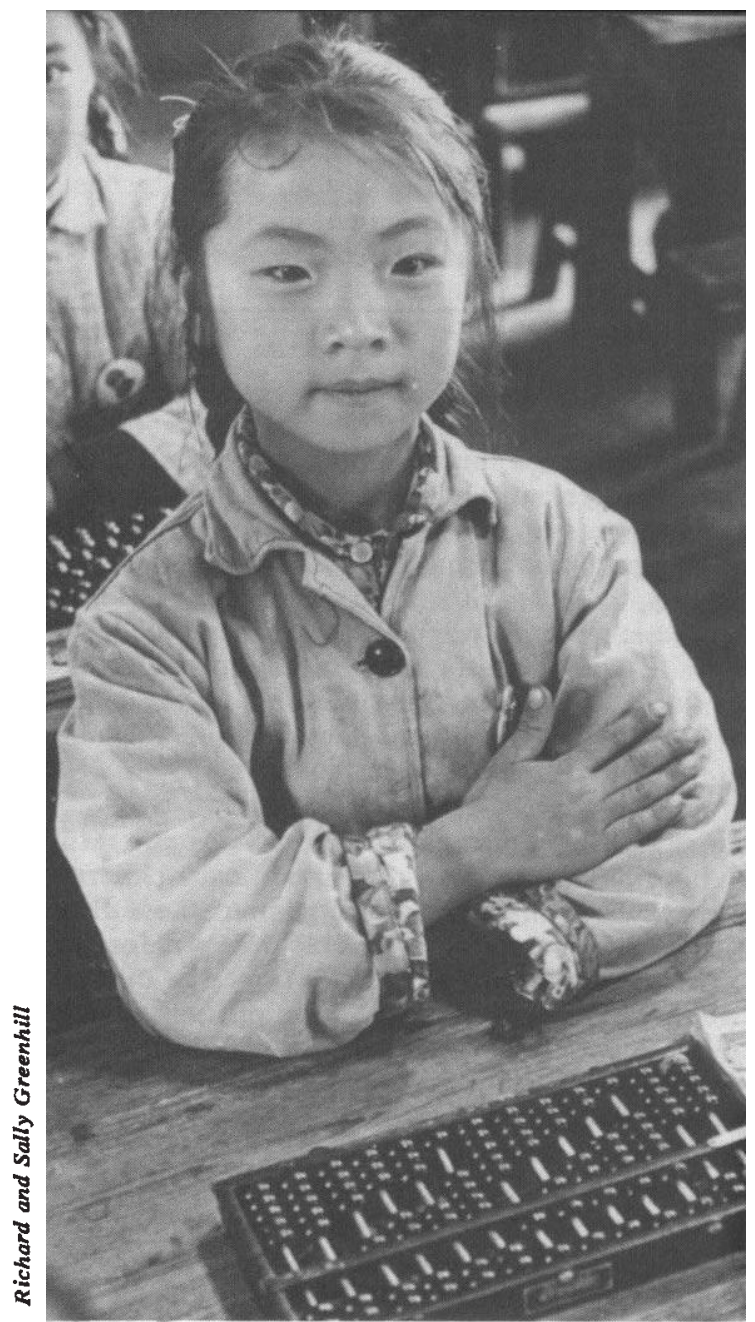

Pupil in a primary school, Nanking, China.

with political rhetoric; the coursework was considerably better organised. Yet students continued to play truant, and many of them continued to be rowdy. A former student from Fujian Province who graduated from senior high school in 1973 and was assigned to a temporary job as a 'monitor' in one of his own school's junior high classes remembers:

These younger kids' attitudes toward study were even worse than my own class's. It was really chaotic in the class. Each classroom had two or three of us monitors, but it made little difference; the kids yelled and horsed around even when the teacher was trying to teach. They didn't know why the heck they were in class. They said studying's useless because their level of achievement wouldn't have any relationship with their futures. I got to know a girl there, whose dad's in the Foreign Ministry and who was a good and willing student. I asked her why, and it turned out she felt she'd have the opportunity to enter a university, through her father. The teacher kept on telling the other kids 'study to construct the country'. Some students were willing to, partly because they also happened to be interested in studying. Most were unwilling.

The same point consistently re-emerged in the interviews, which were conducted in Hong Kong during 1975-76 with nine former students and five former high school teachers from China. ${ }^{2}$ Every one of them insisted that most students had felt it 'useless to study' because success or failure at their schoolwork would have no bearing on their futures.

At the very same time, though, many students were worried about their futures. In China, as in many other late-developing countries, industrial expansion had not kept pace with the baby boom. To avoid high levels of urban unemployment China had begun assigning growing numbers of the new high school graduates to work indefinitely in the countryside. But most of the young people tried to avoid going [Unger 1979]. Among other things, they sensed that the peasant villages had become a dumping grounds for the cities' 'losers'. To help dispel this feeling, the authorities decided that the system of career assignments had to become patently impartial and equitable. Each city devised its own programme, but Canton's was fairly typical. In 1971 it was proclaimed in Canton that any graduating student would be allocated to a rural job, if half or more of his or her brothers and sisters were still in the city. That meant basically that elder siblings went to the countryside, and the younger children in each family got the urban jobs.

The 'backwash' into the schools from this jobassignment policy was profound. Once the students felt their futures were already fated by the order of their births, those destined for the countryside became even less inclined to open their books. They argued to their teachers they would only be able to utilise very rudimentary skills in the villages. Why pay attention to mathematics beyond the multiplication tables when rural accounting techniques used no maths beyond that? Why bother even to learn to recognise rural pests or how to plant rice when they would be learning that anyway once they

\footnotetext{
2 All but three of these 14 interviewees were legal emigrants. Some were Chinese from Southeast Asia who had returned to China with their families in the 1950 s and early $1960 \mathrm{~s}$ and had recently come back out again through Hong Kong. Others were Hong Kong residents whose parents had sent them to Socialist China for their education.
} 
were peasants? It was partly that they felt little preparation was needed for the countryside. But it was partly also, according to respondents, that students did not want to lead the hard and poor life of a peasant. They were consequently refusing to orient themselves toward such a future while still at school. In class some of them openly vented their frustrations and resentments. The final year of senior high school was 'the worst class to try to control', observed a high school teacher from Yunnan Province: "when kids are imminently facing settlement in the countryside, sometimes on purpose they'll sabotage the class period'.

Students who were heading for urban postings were less obstreperous, but only slightly more prone to give any attention to their schoolwork. For one thing, few of them even contemplated going on to a university education. Word had circulated that without entrance examinations or other standardised means for selecting the new university students, Party officials had begun pulling strings and making use of old boy networks. They were getting their children out of the countryside by getting rural officials to nominate the child for a university seat. According to a former Shanghai high school teacher, the young people from other family backgrounds no longer

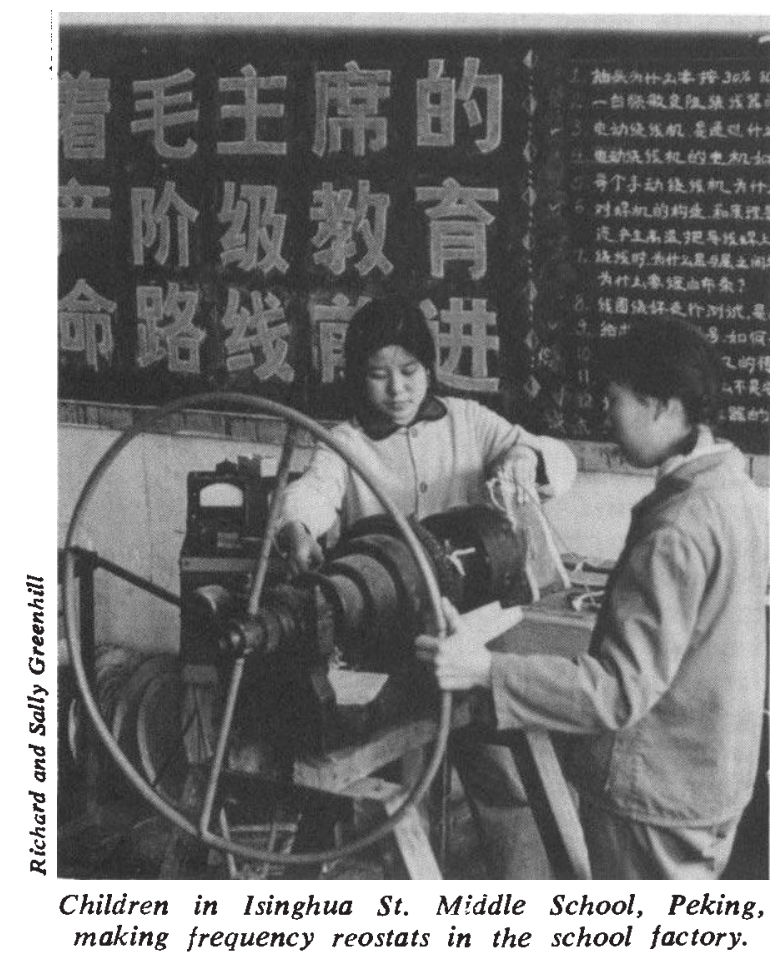

saw any possibility of their own further education, 'just like people don't even think about whether it would be nice or not to live on the moon'.

Many students, even from the intelligentsia only wanted blue collar work. The students were aware that a worker in the early and mid 1970s held a relatively secure political status at a time when 'intellectuals' were politically vulnerable and sometimes harassed. The new desirability and improved status of industrial employment encouraged a growing interest among the students in modern mechanical crafts. This was even true -in fact, especially true-of young people fated for rural assignments, probably because such hobbies represented the type of urban jobs they desired but would not be getting. Students who generally gave little attention to school-work often gravitated, out of school, toward radio building, woodworking, model plane building and the like. At the Fuijian school, where these skills could be practised in 'hobby groups', the interest of students was so great that the school was able to get some of the students to behave better by denying participation to any students who were rowdy during regular classtime.

Some of the students who would be staying in the city had their own reasons for pursuing such hobbies. As part of the new school curriculum, they had engaged in work stints at factories, and interviewees say they and their classmates had become aware of the monotony of routine production line work. In reaction, the hobbies reportedly reflected a desire for interesting blue collar work, such as shop floor mechanics and the like.

The students' views had become more utilitarian in many respects than the school system-and many young people rejected school on these very grounds. They were refusing for pragmatic reasons to pay attention to most of their classes, while at the same time wanting more modern craft skills than they could obtain at school. The radicals who until 1976 were in charge of educaticn had mixed feelings about encouraging desires for even this type of expertise. They felt such an educational orientation was linked to inegalitarian social values. Before the Cultural Revolution, as they pointed out in newspaper editorials, a high regard for expertise had propped up the prestige and salaries of the old professionally trained 'petty bourgeois' classes.

But the Chinese leadership was split. The scientific and military establishments and the 


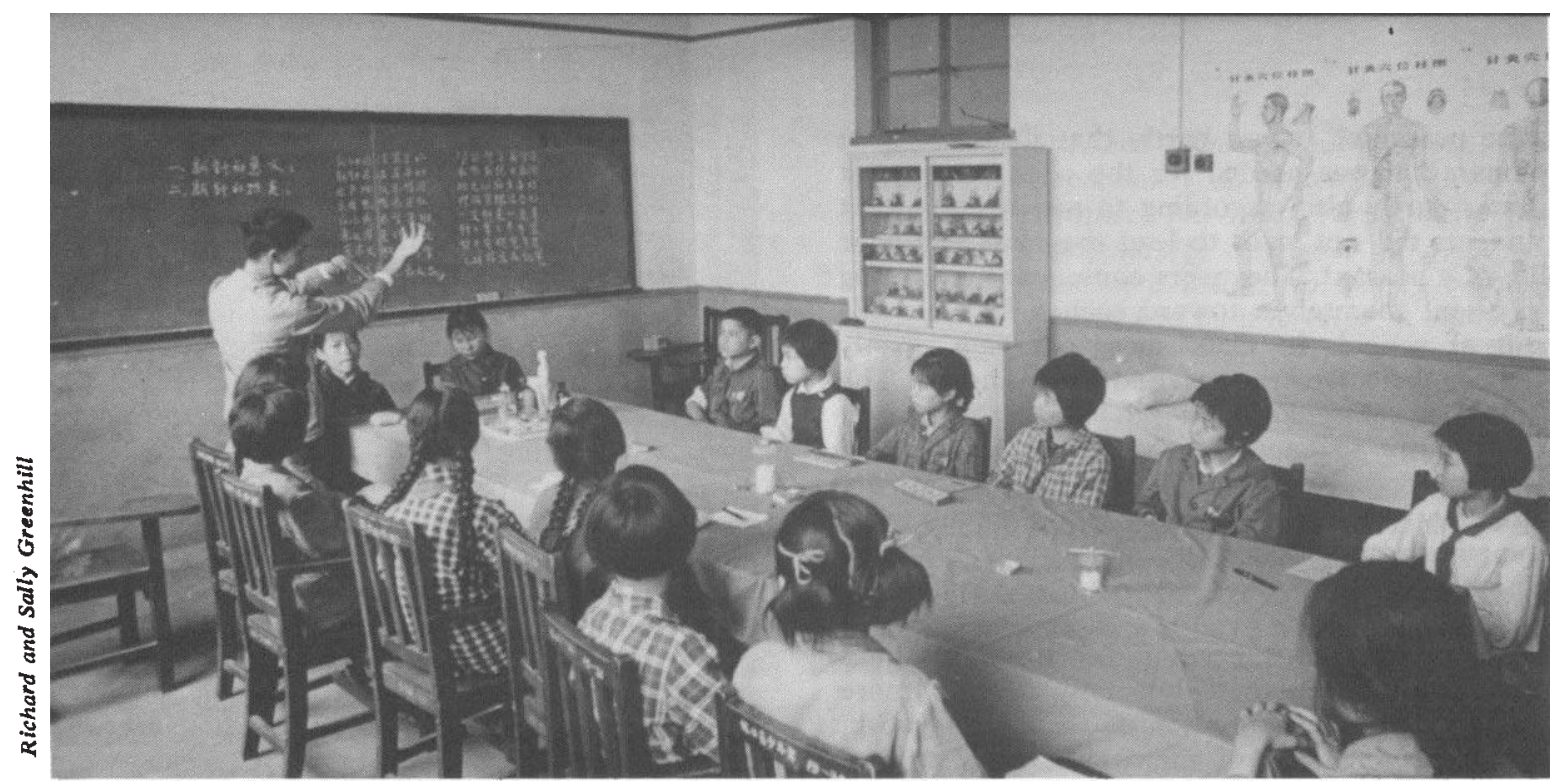

Acupuncture class in Children's Palace, Shanghai.

economic planners were increasingly alarmed at the absence of a new generation of technicians and scientific personnel. They were convinced that all of the radicals' prescriptions for secondary and higher education were endangering China's future [Unger 1980]. After Mao's death in 1976, the new leadership that took power accordingly moved quickly to overturn almost all the innovations in education that had been ushered in with the Cultural Revolution. As officials told a recent visitor in explanation, 'the [radicals'] remedy may have been curing the disease, but it was killing the patient' [Smerling 1979]. The competitive school ladder has been reintroduced, with entrance examinations for junior and senior high school as well as university. The new structure stresses academic 'talent' even more than the pre-Cultural Revolution system; the high schools, for example, have begun tracking students into different classrooms on the basis of their academic achievements. China's newspapers recently have been reporting that many of the symptoms of the diploma disease have already re-appeared: the afterschool private tutors, rote digestion of school material, schools sponsoring weekend 'cramming' sessions, ambitious students exhausting themselves.

\section{Lessons}

What can be learned from China's experiences? It might have been hoped that, if an educational system could be divorced from the competition for careers and if the threat of selection examinations were removed, students would be better able to learn for intrinsic reasons, such as the practicality of the schoolwork.

But this study induced little optimism about the possibilities for wholesale reforms. Admittedly, even in China's mismanaged school system of 1968-76, many students did focus their attention upon modern craft skills, and to an extent greater than the schools encouraged. But it must also be recognised that the social status, political prestige and economic security of China's industrial workers were, all in all, probably higher at that time than the prestige and security of engineers and technicians. It was a situation unlike any other country and temporary even in China, soon to be overthrown along with the Gang of Four. These students, in short, were interested in the skills for desirable jobs; the same students neglected to pay attention to the school lessons on farming. Circumscribing their opportunities had not made them any more satisfied with the low-status occupations, nor oriented them more toward learning the skills involved. If even China, with a national political ideology that actively promoted the dignity of farm work, could not persuade urban students destined for the countryside to pay attention to learning agricultural skills at school, how might other countries expect to promote a similar type of vocational coursework?

In short, educational reforms will not succeed if they ignore students' anxieties and hopes about climbing into desired careers. But there are many 
partial reforms that Third World nations can employ which realistically recognise students' job aspirations but at the same time come to grips with some of the diploma disease's ill effects [eg Dore 1976: 152-63].

China employed an intermediate solution of this type very successfully prior to the Cultural Revolution. China's urban vocational school programme in the $1950 \mathrm{~s}$ and 1960 s was linked to the job market in a way that encouraged the learning of actual vocational skills. The vocational schools' singular advantage was their ability to channel vocational graduates directly into reserved jobs. Unlike China's academic-track senior high schools, whose graduates had to scramble on their own to find jobs, the vocational system in the 1950 s and 1960 s was able to assign its graduates to be the new book-keepers for government offices and factories, the new marine pilots, locomotive engineers, machine-shop craftsmen, etc. These vocational schools' annual enrolments were geared to the projected manpower needs of the various industries and government units; this was to ensure that there would not be any shortages of new skilled personnel.

The results of the programme were impressive. Though the most achievement-oriented urban students in the 1950s and 1960s continued to gamble on the academic-track senior high schools in the hope of getting into a university, in 1965 Canton's full time vocational schools held fully 80 per cent as many students as the academictrack senior high school system; and the competition to get admitted was fairly tight. Most of these vocational students were purposely made ineligible to take the university entrance examinations, so as to prevent them from turning their studies back toward 'examination prepping'. The vocational school administrators very likely supported this regulation, since they were under pressure to supply the government organs with adequately trained personnel.

From 1968 to 1976, however, the doors of many of these vocational schools were closed. ${ }^{3}$ As a recent complaint in China's press observes:

\footnotetext{
3 Under the radicals' scheme, the vocational schools no longer operated as secondary schools. Instead, if a factory needed improved manpower skills of a given kind, it was supposed to select several young workers to attend the appropriate vocational programme. After graduating, the workers were to return to the factory. The municipal education depart ments, however, had run into great difficulties finding enough classrooms and teachers for the new universalised ter year school programme. With this priority in mind, they converted many of the former vocational school facilities into regular schools in the late 1960s. The radicals' vocational training scheme was crippled from the start.
}

Since the Cultural Revolution the ordinary senior high schools blindly have been allowed to expand, and the secondary level specialist schools and the various vocational schools have largely stopped operating. This type of onesided development has [meant that] . . each year the number of senior high graduates is extremely large, and so the ratio of students which the higher educational institutions can admit is very small. This [presently] not only has created a lot of pressure on the institutes of higher education, but also pressures on the senior high to pursue [compete for] favourable rates of university admissions. Even more noteworthy is that over 90 per cent of the senior high graduates will have to participate in manual labour; but they do not have vocational preparation, which gives rise to an acute... demand for skilled labour power. . . .

(Guangming Daily, 5 July 1979: 4)

It now appears China's earlier successful programme will be resurrected in its entirety.

Such an approach to vocational schooling would probably be of considerable benefit to other late developing countries, too. Third World governments normally employ a substantial portion of the personnel in the modern sector. Yet these governments' personnel officers all too frequently operate on the premise that the less capable students are obliged to enter the vocational track, and they accordingly prefer hiring the general education graduates instead. Probably more than anything else, it is this which defeats vocational programmes. In some of these countries, vocational students reportedly do not concentrate on their vocational courses but instead 'prep' to pass the regular-track entrance examinations.

If these Third World governments' regulations stipulated that specified categories of their new middle level technical, administrative, or even blue collar government workers were only to be hired from among the graduates of the appropriate vocational schools, the vocational students could be expected to turn their attention back towards their vocational courses. Perhaps even more important, students in the lower schools would be likely to show a greater interest in learning, the various skills useful for getting into vecational studies.

There may be no complete solution to the diploma disease. But the Chinese vocational training programme of the $1950 \mathrm{~s}$ and 1960 s helps point the way. 
References

Dore, R. P., 1976, The Diploma Disease, Allen \& Unwin, London

Guangming Daily, Peking

Smerling, Louis, 1979, 'Admissions', in Ronald Montaperto (ed), China's Schools in Flux, M. E. Sharpe Inc, White Plains, NY
Unger, Jonathan, 1979, 'China's troubled downto-the-countryside campaign', Contemporary China, vol 3 no 2, Summer

-1980, 'The Chinese controversy over higher education, Pacific Affairs, Spring

-forthcoming, Education Under Mao: a Study of Canton Schools 1960-78 